\title{
Some Fiscal Implications of Monetary Policy
}

\author{
Harris Dellas \\ Department of Economics \\ University of Bern
}

\author{
Kevin D. Salyer \\ Department of Economics \\ University of California, Davis
}

April 2001

\begin{abstract}
We study the implications of alternative monetary targeting procedures for real interest rates and economic activity. We find that countercyclical monetary policy rules lead to higher real interest rates, higher average tax rates, lower output but lower variability of tax rates and consumption relative to procyclical rules. For a country with a high level of public debt (e.g. Italy), the adoption of a countercyclical procedure such as interest rate pegging may conceivably raise public debt servicing costs by more than half a percentage point of GNP. Our analysis suggests that the current debate on the targeting procedures of the European Central Bank ought to be broadened to include a discussion of the fiscal implications of monetary policy. ${ }^{1}$
\end{abstract}

\footnotetext{
${ }^{1}$ We are indebted to seminar participants at the Federal Reserve Bank of St. Louis and the Western Economic Association meetings for helpful comments. In addition, two anonymous referees improved significantly the exposition of the paper.
} 


\section{Introduction}

The influence of monetary policy on real variables is a classic issue and has naturally attracted enormous theoretical and empirical scrutiny. An important subset of this literature has been devoted to the investigation of the relationship between money and interest rates, and in particular to the issue of neutrality, that is, whether changes in the nominal money stock affect real interest rates (Friedman and Schwartz (1963), Tobin (1965), Sidrauski (1967), Haraf and Cagan (1990); see also the references in Orphanides and Solow (1990) and Woodford (1990)). ${ }^{2}$

Regarding this issue it is now accepted that long term real rates are, for practical purposes, beyond the influence of the supply of money; they are instead influenced by technological factors, preferences, demographics and tax policies etc. ${ }^{3}$ While there is some disagreement pertaining to the importance of monetary factors for short term interest rates, the majority view claims significant non-neutralities that arise from either price rigidities, imperfect information, or trading frictions.

The objective of this paper is to study the effects that monetary policy has for interest rates and the burden of government debt within a simple economy in which the probability

\footnotetext{
${ }^{2}$ It is important to state at the outset precisely what we mean by monetary neutrality. We use the following taxonomy. Within the context of non-stochastic, static economies neutrality refers to the effects caused by changes in the money stock. In deterministic dynamic economies, analysis of the effects of changes in the monetary growth rate is referred to as superneutrality. This concept extends to dynamic, stochastic settings, i.e. those characterized by randomness in the growth rate of money, when changes in the unconditional mean of money growth are studied. When the effects of a particular realization of the money growth rate are studied, this analysis is a question of dynamic neutrality.

${ }^{3}$ Of course, there exist numerous monetary models where monetary superneutrality breaks down (for some representative models, see Stockman (1980), Aschauer and Greenwood (1983)). In spite of these theoretical demonstrations, a convincing empirical documentation of non-negligible effects of money growth on the allocation of resources is lacking. For instance, see Cooley and Hansen's (1989) analysis of the inflation tax in a cash-inadvance economy.
} 
distribution of money is not degenerate. Unlike the majority of existing analyses cast within stochastic settings, we focus on the role of the second moments of money growth rather than the first. This allows us to relate cyclical monetary policy to real economic activity. To isolate the contribution of monetary policies as it relates to the business cycle we conduct the analysis within a model in which the first moment of money does not affect real variables; that is, money is neutral in the traditional sense. We then ask whether alternative monetary policy procedures produce differences in the behavior of real variables and the allocation of resources. A negative response to this question implies a broadening of the traditional concept of neutrality.

We compare alternative monetary policy rules within a stochastic cash-in-advance model with technological and fiscal uncertainty. Within this environment, we demonstrate that the choice of the policy rule does indeed matter even though the economy exhibits dynamic neutrality. One important reason for this result is that, in the presence of uncertainty, different monetary policy rules imply different values for risk premia on nominal assets. ${ }^{4}$ According to the consumptionbased capital asset pricing model, the risk premium on a nominal asset depends on the covariance between consumption and the inflation rate. When the economy is subject to exogenous shocks, this covariance can be affected by monetary policy regardless of whether consumption is invariant to a change in the supply of money (as it is under money neutrality in the classical model) or not (as it is in the Keynesian model). We show that a procyclical monetary policy is associated with lower average real interest rates relative to those in an economy with a countercyclical policy.

One can focus on several empirical implications of this result concerning the relationship

\footnotetext{
${ }^{4}$ The role of monetary policy in influencing relative prices (e.g. real interest rates) has been investigated by among others, Lucas (1982), LeRoy (1984), and Svensson (1985). Those studies, however, employed exchange economies - so there are no repercussions for the allocation of resources - and, moreover, they did not address explicitly the issue of how the cyclical properties of the money supply affect relative prices.
} 
between the allocation of resources and the choice of the policy regime. There are, however, two aspects that seem particularly interesting. The first regards a fiscal consideration of obvious practical importance. If alternative monetary policies lead to different average real interest rates then they will also lead to differences in the size of interest payments (and hence tax revenues) required for servicing public debt. ${ }^{5}$ For example, consider a country such as Italy. If its average real rates on public debt under a countercyclical rule are higher by fifty basis points -and our calibration results indicate that such a figure is quite plausible- then the adoption of a countercyclical rule may impose an annual cost on the fiscal authorities on the order of a half to one percent of GNP. This is quite substantial. ${ }^{6}$

The second important consequence comes from the relationship between higher debt payments and the associated tax burden. Differences in average tax revenues across alternative monetary policy regimes will translate into differences in average tax rates (and hence in differences in the tax burden of public debt). ${ }^{7}$ As higher taxes discourage economic activity, different monetary regimes will also carry different costs in terms of real income. Our results suggest that countercyclical money rules will be the most costly in terms of resource allocation and real income losses.

The rest of the paper is organized as follows. Section 2 presents the benchmark case of risk premia in the model with lump sum taxes while Section 3 introduces distortionary taxes. Concluding remarks are offered in Section 4.

\footnotetext{
${ }^{5}$ This statement is made under the proviso that there are no offsetting differences in average seigniorage collection across policy rules.

${ }^{6}$ Recent estimates of the inflation risk premium in the U.K. by Shen (1998) are on the order of 100 basis points implying even greater fiscal implications.

${ }^{7}$ Again this is conditional on assuming seigniorage is equal across policy regimes.
} 


\section{Lump-Sum Taxes}

It is assumed that the economy is populated by identical, infinitely lived individuals who produce a single, perishable perfectly divisible good. The representative agent's level of utility depends on consumption and leisure and is separable both intertemporally and intratemporally. The agent's expected discounted sum of lifetime utility is given by:

$$
E_{0} \sum_{t=0}^{\infty} \beta^{t}\left[u\left(c_{t}\right)+v\left(1-n_{t}\right)\right]
$$

where $E$ is the expectations operator, $\beta \in(0,1)$ is the discount factor, $u(\cdot)$ and $v(\cdot)$ are utility functions satisfying the standard conditions, $c_{t}$ is consumption and $\left(1-n_{t}\right)$ is leisure in period $t$.

Production is carried out by identical, perfectly competitive firms according to the stochastic production technology

$$
y_{t}=z_{t} f\left(n_{t}\right)
$$

where $f(\cdot)$ is a production function with the standard properties, $n_{t}$ and $y_{t}$ are work effort and output respectively and $z_{t}>0$ is an i.i.d. technological (productivity) shock. The firms' hiring decisions are assumed to be made after observing the value of the shock.

Money enters via a cash-in-advance constraint that requires consumption goods to be purchased with cash. Money is injected into (or withdrawn from) the economy by the government through lump-sum transfers. In addition, the government imposes lump-sum taxes (makes lumpsum transfers), issues one period nominal public debt and faces an exogenously given stream of 
public expenditure. ${ }^{8}$ Like private agents, the government is also subject to a cash-in-advance constraint when purchasing goods. In addition to money and nominal public debt, individuals are assumed to hold equity shares in the firms. Other assets can be allowed provided their introduction does not undermine the existence of the cash-in-advance constraint and nominal public debt.

The setup of the model so far has been standard. ${ }^{9}$ If we continue to follow the traditional route in the specification of the timing of markets and transactions then it is well known that money will not be superneutral or dynamically neutral. This is due to the fact that, in such a specification, nominal labor income is received with a one period lag implying the contemporaneous labor-leisure choice will be sensitive to the expected inflation rate and hence the nominal interest rate (see e.g., Aschauer and Greenwood (1983)). This breakdown of dynamic and super-neutrality in cash-in-advance models with variable factors of production is well established (Wilson (1979), Stockman (1980)). In contrast to this literature, our objective and valued added of this paper - is to investigate the implications of the cyclical conduct of monetary policy; that is, second rather than first moment effects. The best way of carrying out this task is by eliminating any first moment effects. Consequently, we will operate with a timing of markets that generates standard neutrality by eliminating the inflation tax on labor income. There are several specifications that will produce this; we discuss one of them below.

Each period is divided into three sub-periods or sessions. The first occurs at the beginning of the period; at this time, the labor market opens and firms make their hiring decisions after

\footnotetext{
${ }^{8}$ The assumption of short term debt is convenient in that it does not introduce term structure considerations into our analysis. However, it is not critical for our results.

${ }^{9}$ The model is basically a stochastic variant of Wilson (1979). However, as described below, we modify the setup so that money is superneutral, i.e. the inflation tax on labor earnings is eliminated.
} 
having observed the current realization of the technological shock. At the same time, the workers make their leisure-consumption decision. The information set at this point contains information on the value of government expenditure, taxes (transfers), debt issues, and the money supply. Hence, there is no longer any uncertainty left in the system and the current period price level is known.

In the second session, the following events take place: firms produce output while the government retires outstanding debt, issues new bonds, levies lump-sum taxes and makes lump-sum transfers. During the same session the firms distribute the profits and pay the salaries that are associated with current production. These payments are financed by the revenue earned during the previous period. In order to make sure that the firms have enough cash to cover current production costs we allow them to issue an asset that may make negative dividend payments to its holders. Finally, during this session the consumers decide how much cash to put aside to be used for purchasing consumption later during the goods market.

The third trading session takes place in the goods market during which both the government and consumers buy goods from the firms.with current cash holdings.

We summarize below the sequence of events within each period. $M_{t}, m_{t}, B_{t}^{c}, B_{t}^{g}, T_{t}$, $p_{t}, R_{t}, w_{t}$, are the supply of money, individual money holdings, the quantity of public debt demanded by the consumers, the quantity of public debt supplied by the government, lump-sum taxes (transfers), price level, interest rate on public debt, and labor wage respectively. All these variables are in nominal terms. The individual also holds two types of stocks: the first stock, of which he holds $k_{t}$ units, entitles him to receive a share of the profits of the firm; the other, of which he holds $\zeta_{t}$ units, pays a dividend that is equal to the difference between the cash the firm has at its disposal before selling its goods to the consumers and the wage bill (the total 
number of shares in normalized to be equal to unity). The two types of equity trade at the price of $Q_{1 t}$ and $Q_{2 t}$ respectively.

This description implies the following chronology:

Table 1: Timing of events in each period

\begin{tabular}{|c|c|l|}
\hline Session 1: $z_{t}$ observed & \multicolumn{1}{|c|}{ Session 2 } & \multicolumn{1}{c|}{ Session 3 } \\
\hline $\begin{array}{c}\text { Agents: choose }\left(c_{t}, n_{t}, m_{t}\right) \\
\text { Firms: choose }\left(n_{t}\right)\end{array}$ & Firms: pay $\left(w_{t}, \pi_{t}, \vartheta_{t}\right)$ & Firms: sell $y_{t}$ \\
& Govt.: $\operatorname{set}\left(T_{t}, B_{t}^{g}, M_{t}\right)$ & Govt.: $m_{t}^{*} \geq p_{t} g_{t}$ \\
\hline
\end{tabular}

This implies the following constraints:

The firm makes salary and profit payments with money received from sales in the previous period and the (possibly negative) dividend payments associated with the second type of equity discussed above. Therefore its budget constraint is

$$
p_{t-1} y_{t-1}=w_{t} n_{t}+\pi_{t}+\vartheta_{t}
$$

where $\vartheta_{t} \equiv\left(p_{t-1} y_{t-1}-w_{t} n_{t}-\pi_{t}\right)$. Note that this quantity is treated as given by the agents.

The budget constraint of the worker/consumer is:

$$
\begin{gathered}
w_{t} n_{t}+k_{t-1}\left(\pi_{t}+Q_{1 t}\right)+\zeta_{t-1}\left(\vartheta_{t}+Q_{2 t}\right)+\left(1+R_{t-1}\right) B_{t-1}^{c}+\left(m_{t-1}-p_{t-1} c_{t-1}\right)-p_{t} T_{t} \\
\geq B_{t}^{c}+m_{t}+Q_{1 t} k_{t}+Q_{2 t} \zeta_{t}
\end{gathered}
$$

The budget constraint of the government is: 


$$
m_{t}^{*}=M_{t}-M_{t-1}-\left(1+R_{t-1}\right) B_{t-1}^{g}+B_{t}^{g}+p_{t} T_{t}
$$

where $m^{*}$ is cash used to finance government purchases (denoted $g_{t}$ ) and $T$ denotes (real) taxes or transfers. As we are abstracting from the optimal determination of fiscal and monetary policy we will assume that the paths of $g_{t}\left(\right.$ with $\left.g_{t} \leq z_{t} f\left(n_{t}\right)\right)$ and $b_{t}^{g}=B_{t}^{g} / p_{t}$ are given exogenously and the government's choice variables are $T_{t}$ and $M_{t}$.

The agents and the government use cash holdings to finance consumption

$$
\begin{aligned}
& m_{t} \geq p_{t} c_{t} \\
& m_{t}^{*} \geq p_{t} g_{t}
\end{aligned}
$$

With the description of the timing of the markets as well as the events occurring in each trading session complete, we now turn to the optimization problems faced by the firms and consumer-workers respectively.

Maximization of profits by the firm requires equating the wage to the marginal revenue product of labor in every period:

$$
w_{t}=p_{t} z_{t} f^{\prime}\left(n_{t}\right)
$$

The household's maximization problem can be formulated as a dynamic programming problem by first noting that agents wealth along with labor income is used in every period to acquire bonds, equity and new money. Letting $\gamma_{t}$ denote real wealth, this implies the following constraint: 


$$
\gamma_{t}+\frac{w_{t}}{p_{t}} n_{t}=\frac{B_{t}^{c}}{p_{t}}+\frac{Q_{1 t}}{p_{t}} k_{t}+\frac{Q_{2 t}}{p_{t}} \zeta_{t}+\frac{m_{t}}{p_{t}}+T_{t}
$$

The law of motion of real wealth is determined by money carried over from the goods market and the returns on equity and bonds as given by the following expression:

$$
\gamma_{t+1}=\left[\left(m_{t}-p_{t} c_{t}\right)+k_{t}\left(\pi_{t+1}+Q_{1 t+1}\right)+\zeta_{t}\left(\vartheta_{t+1}+Q_{2 t+1}\right)+B_{t}^{c}\left(1+R_{t}\right)\right] / p_{t+1}
$$

Letting $V(\cdot)$ denote the value function, the consumer's maximization problem can be written as the following dynamic programming problem:

$$
V\left(\gamma_{t}, z_{t}, M_{t}\right)=\max _{\left(c_{t}, n_{t}, m_{t}, B_{t}^{c}, Q_{1 t}, Q_{2 t}\right)}\left\{u\left(c_{t}\right)+v\left(1-n_{t}\right)+\beta E_{t}\left[V\left(\gamma_{t+1}, z_{t+1}, M_{t+1}\right)\right]\right\}
$$

subject to the wealth constraint, eq.(2.9) and the cash-in-advance constraint, eq. (2.6). Note that $E_{t}$ denotes the expectations operator with respect to the conditional distribution describing the motion of the technology shock and the money supply (the economy-wide state variables).

Let $\alpha_{t}$ and $\lambda_{t}$ be the Lagrange multipliers associated with constraints (2.6) and (2.9) respectively. The resulting first order conditions are: ${ }^{10}$

$$
\begin{gathered}
u_{t}^{\prime}-\beta E_{t}\left[\lambda_{t+1} \frac{p_{t}}{p_{t+1}}\right]-\alpha_{t}=0 \\
\lambda_{t} \frac{w_{t}}{p_{t}}-v_{t}^{\prime}=0
\end{gathered}
$$

\footnotetext{
${ }^{10}$ In deriving the necessary conditions, the envelope theorem has been used. That is, $\frac{\partial V_{t}}{\partial \gamma_{t}}=\lambda_{t}$ for all $t$.
} 


$$
\begin{gathered}
\beta E_{t}\left[\lambda_{t+1} \frac{1}{p_{t+1}}\right]-\lambda_{t} \frac{1}{p_{t}}+\alpha_{t} \frac{1}{p_{t}}=0 \\
\beta E_{t}\left[\lambda_{t+1} \frac{1}{p_{t+1}}\right]\left(1+R_{t}\right)-\lambda_{t} \frac{1}{p_{t}}=0 \\
\beta E_{t}\left[\lambda_{t+1} \frac{\left(Q_{1 t+1}+\pi_{t+1}\right)}{p_{t+1}}\right]-\lambda_{t} \frac{Q_{1 t}}{p_{t}}=0 \\
\beta E_{t}\left[\lambda_{t+1} \frac{\left(Q_{2 t+1}+\vartheta_{t+1}\right)}{p_{t+1}}\right]-\lambda_{t} \frac{Q_{2 t}}{p_{t}}=0
\end{gathered}
$$

Note that eqs. (2.12) and (2.14) imply that the marginal utility is equal to the Lagrange multiplier associated with the wealth constraint. This is a consequence of the goods market following the asset market. More important for our purposes, note that this result in combination with the necessary conditions associated with agent's labor-leisure trade-off (eq. (2.13)) and firm's profit maximization (eq. (2.8)) imply

$$
v_{t}^{\prime} / u_{t}^{\prime}=z_{t} f^{\prime}\left(n_{t}\right)
$$

We can now define an equilibrium.

Definition: An equilibrium is a set of initial conditions $M_{0}$ and $B_{0}$, and stochastic processes for $\left\{n_{t}, c_{t}, m_{t}, m_{t}^{*}, k_{t}, \zeta_{t}, T_{t}, M_{t}, b_{t}, p_{t}, w_{t}, q_{t}, Q_{1 t}, Q_{2 t}, \pi_{t}, \vartheta_{t}\right\}$ such that:

a) The government budget and finance constraints (2.5) and (2.7) are satisfied and $m_{t}^{*}=p_{t} g_{t}$.

b) Given the sequences $\left\{p_{t}, q_{t}, w_{t}, R_{t}, Q_{1 t}, Q_{2 t}\right\}$ and the initial conditions $M_{0}$ and $B_{0}$, the stochastic processes for $\left\{c_{t}, n_{t}, m_{t}, b_{t}, k_{t}, \zeta_{t}\right\}$ satisfy (2.9)-(2.16).

c) $M_{t}=m_{t}+m_{t}^{*}$.

d) $B_{t}^{c} / p_{t}=B_{t}^{g} / p_{t}=b_{t}$.

e) $k_{t}=\zeta_{t}=1$ 
f) The economy's resource constraint is satisfied:

$$
g_{t}+c_{t}=z_{t} f\left(n_{t}\right)
$$

By placing appropriate restrictions on the distribution describing the motion of the technology shock and the money supply, we can focus on equilibria with strictly positive nominal interest rates, $R_{t}>0, \forall t$. This implies that the cash-in-advance constraints hold as strict equalities and subsequently, $M_{t}=p_{t}\left(g_{t}+c_{t}\right)=z_{t} f\left(n_{t}\right)$.

Using (2.19) for $c_{t}$ in equation (2.18) produces the following equation in $n_{t}$

$$
v^{\prime}\left(1-n_{t}\right) / u^{\prime}\left(z_{t} f\left(n_{t}\right)-g_{t}\right)=z_{t} f^{\prime}\left(n_{t}\right)
$$

which shows immediately that the level of effort (and hence consumption) in period $t$ is solely a function of the exogenous productivity shock, $z_{t}$. The properties of $u, v$ and $f$ imply that the solution to (2.20) is unique. Subsequently, money is perfectly neutral regarding the labor-leisure choice, as well the intertemporal allocation of resources. We will now turn to the examination of the relationship between alternative monetary rules and real interest rates.

\subsection{Stabilization Policy and Real Interest Rates}

Using (2.15) (and the result that $u_{t}^{\prime}=\lambda_{t}$ ) one can solve for the nominal interest rate, $R_{t}$

$$
\left(1+R_{t}\right)^{-1}=\beta E_{t}\left[\left(\frac{u^{\prime}\left(z_{t+1} f\left(n_{t+1}\right)-g_{t+1}\right)}{u^{\prime}\left(z_{t} f\left(n_{t}\right)-g_{t}\right)}\right)\left(\frac{p_{t}}{p_{t+1}}\right)\right]
$$

The ex-ante real interest rate, $r_{t}$, is the nominal interest rate adjusted for expected inflation 


$$
\left(1+r_{t}\right)=\left(1+R_{t}\right) E_{t}\left(p_{t} / p_{t+1}\right)
$$

Using (2.21), equation (2.22) can be written as

$$
\left(1+r_{t}\right)^{-1}=\beta E_{t}\left[\frac{u_{t+1}^{\prime}(\cdot)}{u_{t}^{\prime}(\cdot)}\right]+\beta \operatorname{Cov}_{t}\left[\frac{u_{t+1}^{\prime}(\cdot)}{u_{t}^{\prime}(\cdot)},\left(\frac{p_{t}}{p_{t+1}}\right)\right] / E_{t}\left(\frac{p_{t}}{p_{t+1}}\right)
$$

where $\operatorname{Cov}_{t}$ denotes conditional covariance.

We will now study the behavior of ex-ante real interest rates under two monetary policy rules: One involves the stabilization of the nominal interest rate at some level $R^{\prime}, \forall t$. It can be seen from equation (2.21) that interest rate pegging essentially entails the manipulation of the money supply according to the rule: $u^{\prime}(t) / p_{t}=\xi_{t}$, where $\xi_{t+1} / \xi_{t}=\left(1+R^{\prime}\right) \beta$ and $p_{t}=M_{t} / z_{t} f\left(n_{t}\right)$. The other rule ${ }^{11}$ aims at stabilizing the price level at some level $p$ and requires that the money supply in period $t, M_{t}$, is set according to the rule $M_{t}=p z_{t} f\left(n_{t}\right) \cdot{ }^{12}$

Proposition: A price level stabilization policy leads to lower real interests rate than a nominal interest rate pegging policy.

The proof of this proposition is as follows: The first term in (2.23) is independent of the policy regime (because of equation (2.20). Subsequently, the comparison of real interest rates across the two targeting procedures depends on the covariance term in equation (2.23). Whether the shock comes from the supply $\left(z_{t}\right)$ or the demand $\left(g_{t}\right)$ side, the covariance is zero under price

\footnotetext{
${ }^{11}$ Other distinct rules, such as targeting the money supply, can be similarly analyzed.

${ }^{12}$ These two monetary policy regimes are chosen primarily for pedagogical reasons. As discussed later in this section, the important distinction between regimes is the implied cyclical behavior of prices, i.e. whether equilibrium prices are pro- or countercyclical. While the two regimes studied here are useful for expository purposes, the results generalize to other regimes such as a money growth rule or a Taylor rule.
} 
stabilization. On the other hand, it is always negative under an interest rate rule. This is due to the fact that a pegged nominal interest rate requires an expectation that any change in $u_{t+1}^{\prime} / u_{t}^{\prime}$ will be met by an offsetting change in $p_{t} / p_{t+1}$ (see equation (2.21). Subsequently, an interest rate rule gives rise to positive risk premia on a nominally denominated asset due to the fact that it delivers low inflation (and therefore a high real return) in periods of high consumption growth and vice versa (a procyclical pattern for the real rate of return). This is true independent of whether the shock originates in the demand or the supply side.

Note that the policy rules we have considered can easily be generalized in terms of a response function, $g(\cdot)$, so that $M_{t}=g\left[z_{t} f\left(n_{t}\right)\right]$. The effects on the risk premium term in $(2.23)$ under alternative assumptions about the properties of $g(\cdot)$ can then be studied. While this is straightforward, some caution must be exercised in the choice of $g(\cdot)$ so that the nominal interest rate is not driven to zero (recall that the equilibrium described above is conditional on a binding cash-in-advance constraint). With that caveat, it can be immediately seen that the risk premium is a positive function of the degree of policy countercyclicality due to the implications for the covariance term in equation (2.23). That is, if the money supply is negatively correlated with output, $g^{\prime}\left[z_{t} f\left(n_{t}\right)\right]<0$, this will exacerbate the covariance between agents' consumption and the real return on nominal bonds leading to a positive risk premia associated with nominal bonds. Sufficiently procyclical rules can even lead to negative risk premia and consequently such rules will be associated with the lowest real interest rates. Note also that one can think in terms of picking a real interest rate target and choosing monetary policy to satisfy that target.

The analysis has suggested that the choice of the targeting procedure influences the level of real interest rates. Nevertheless the important question concerns not so much the theoretical possibility but rather the quantitative importance of these effects. While this is ultimately an 
empirical matter that requires the decomposition of real interest rate into its various components, a simpler, informative alternative exists. ${ }^{13}$ Equation (2.23) can be calibrated based on the actual stochastic process of consumption in any country under consideration. Suppose that the log of consumption follows a random walk (alternative specifications can be easily accommodated).

More specifically let

$$
c_{t+1}=c_{t} \varphi_{t+1}
$$

A standard formulation for the utility function is

$$
u_{t}=\frac{c_{t}^{1-\theta}-1}{1-\theta} \text { for } \theta \neq 1 \text { and } u_{t}=\ln c_{t} \text { for } \theta=1
$$

Subsequently, the ex ante real interest rate can be written as

$$
1+r^{p}=\frac{1}{\beta E_{t} \varphi_{t+1}^{-\theta}}
$$

under inflation targeting and

$$
1+r^{i}=\frac{E_{t} \varphi_{t+1}^{\theta}}{\beta}
$$

under nominal interest targeting. We have assumed a zero drift rate of inflation under nominal interest rate targeting, that is, $\xi p_{t+1}=u_{t+1}^{\prime}$ which implies that $R_{t}=1 / \beta$ for all $t$.

\footnotetext{
${ }^{13}$ See Shen (1998) for precisely this kind of decomposition of interest rates using data from the U.K. on nominal yields, yields on indexed bonds, and expectations of inflation. As stated earlier, this analysis finds evidence of a substantial (100 basis points) inflation risk premium on nominal debt.
} 
Assuming that $\varphi$ follows a lognormal distribution such that $\log \varphi$ is $N\left(0, \sigma^{2}\right)$ and taking $\operatorname{logs}$ in (2.26) and (2.27) results in

$$
r^{i}-r^{p} \cong \theta^{2} \sigma^{2}
$$

One can now calculate the implications of monetary policy for real interest rates using equation (2.28) together with values for the coefficient of relative risk aversion and the variance of consumption in individual countries. Table 2 reports the differences in real interest rates as a function of $\theta$ in two heavily indebted countries, Belgium and Italy. Real interest rates in other countries can be similarly calculated. We computed $\sigma^{2}$ from a regression of $\log \left(c_{t}\right)$ on $\log \left(c_{t-1}\right)^{14}$. The resulting values for Italy and Belgium are 0.000625 and 0.00040 respectively. The implications are striking. While there exists no consensus view about the size of the coefficient of relative risk aversion, values between zero and four are widely accepted as plausible. Even for low values of $\theta$, the choice of operating procedure seems to make a big difference. For $\theta=3$, nominal interest rate pegging in Italy can increase public debt servicing costs by an amount close to half a percentage point of GNP; the difference climbs to eighty basis points when $\theta=4$. Note, that the relevant concept of debt is medium and long term, nominal, domestic currency debt. The numbers reported here use this measure of debt ${ }^{15}$.

\footnotetext{
${ }^{14}$ ITALY: $\log \left(c_{t}\right)=0.98 \log \left(c_{t-1}\right)$, s.e $=0.025$

BELGIUM: $\log \left(\mathrm{c}_{t}\right)=0.98 \log \left(c_{t-1}\right)$, s.e $=0.020$

Total private consumption expenditure, annual data, 1952-1993 (source: IFS).

${ }^{15}$ Italy's Debt/GNP ratio is 1.25 and Belgium's 1.38. The share of foreign currency debt in total debt is negligible: about $5 \%$ in Italy and close to zero in Belgium. The share of long term debt in total domestic curency debt is about $70 \%$ in Italy and almost $100 \%$ in Belgium.
} 
Table 2: Interest Rate Differences (in basis points)

\begin{tabular}{|c|cc||cc|}
\hline & \multicolumn{2}{|c||}{ Italy } & \multicolumn{2}{c|}{ Belgium } \\
$\theta$ & $r^{i}-r^{p}$ & Cost (\% of GDP) & $r^{i}-r^{p}$ & Cost (\% of GDP) \\
\hline 0 & 0 & 0 & 0 & 0 \\
1 & 6 & 0.05 & 0.20 & 0.05 \\
2 & 25 & 0.33 & 25 & 0.34 \\
2.5 & 40 & 0.46 & 36 & 0.49 \\
3 & 56 & 0.82 & 64 & 0.84 \\
4 & 100 & & & \\
\hline
\end{tabular}

In this model, differences in real interest rates across monetary policy regimes do not translate into differences in the allocation of resources. This is due to the assumption of lump-sum taxation. While more tax revenue is raised to service the higher interest liabilities on public debt, this does not create any distortions. In the following section, we carry out the same analysis for the more realistic case of distortionary income taxation.

\section{An Income Tax}

The model is identical to that of the previous section with the exception that the government no longer has access to non-distortionary taxes. We assume - without addressing its optimality - that the tax in use is one on current income other than interest income (on labor earnings and dividends) and that it is applied at the rate $\tau_{t}$. The previous description of the economy remains intact with a few changes: the replacement of $w_{t}$ with $\left(1-\tau_{t}\right) w_{t}$ in equations (2.4), (2.9) and (2.13); and $\pi_{t}$ is replaced by $\left(1-\tau_{t}\right) \pi_{t}$. Real tax revenue now becomes $T_{t}=\tau_{t} z_{t} f\left(n_{t}\right)$ and equation (2.20) which determines the equilibrium level of work effort is now written as: 


$$
v^{\prime}\left(1-n_{t}\right) / u^{\prime}\left(z_{t} f\left(n_{t}\right)-g_{t}\right)=\left(1-\tau_{\tau}\right) z_{t} f^{\prime}\left(n_{t}\right)
$$

Before proceeding with the comparison of risk premia across alternative monetary rules we make the following simplifying assumptions:

a) The economy operates on the upward sloping part of the Laffer curve, that is, $d T_{t} / d \tau_{t}>0$. This implies that higher tax revenues require higher tax rates.

b) The average amount of seigniorage is zero under both regimes. This implies that differences in interest rates are not due to differences in the revenue sources for the government. Any non-zero number can be accommodated as long as it is the same under alternative regimes.

c) The debt policy is such that debt issuance is unitary elastic with regard to the inflation rate. This implies that the (exogenous) path of real debt is independent of the monetary policy regime. To keep things simple we will further assume a constant level of real debt. We make this assumption because, like our assumption on seigniorage, it forces the monetary regimes to differ only in a single dimension (that regarding risk premia). ${ }^{16}$ Hence, it makes the comparison of tax rates across policy regimes in each period more clear by not allowing -arbitrary- differences in the covariance of public debt issues with the productivity shocks to be mapped into differences in tax revenues across regimes.

Tax collections in period $t+1$ under a price stabilization rule (denoted by a $p$ subscript), $p_{t}=p$ for all $\mathrm{t}$, are given by

$$
T_{t+1}^{p}=\tau_{t+1}^{p} z_{t+1} f\left(n_{t+1}^{p}\right)=g_{t+1}+\left(1+R_{t}^{P}\right) \frac{B_{t}^{p}}{p}-\frac{B_{t+1}^{p}}{p}-\frac{M_{t+1}^{p}-M_{t}^{p}}{p}
$$

And under a nominal interest rate targeting rule (denoted by an $i$ superscript) by

\footnotetext{
${ }^{16}$ Realism is not a relevant consideration here as we have already assumed that the path of real debt is exogenously given. Chari, Christiano and Kehoe $(1991,1994)$ study fiscal policy but do not address the issue of cyclicality in monetary policy.
} 


$$
T_{t+1}^{i}=\tau_{t+1}^{i} z_{t+1} f\left(n_{t+1}^{i}\right)=g_{t+1}+\left(1+R_{t}^{i}\right) \frac{p_{t}^{i}}{p_{t+1}^{i}} \frac{B_{t}^{i}}{p_{t}^{i}}-\frac{B_{t+1}^{i}}{p_{t+1}^{i}}-\frac{M_{t+1}^{i}-M_{t}^{i}}{p_{t+1}^{i}}
$$

Under a price level target, $M_{t+1}^{p} / p=y_{t}^{p}$. Under interest rate pegging, $p_{t}^{i} / p_{t+1}^{i}=u_{t}^{i^{\prime}} / u_{t+1}^{i^{\prime}}$ and subsequently, $\left(M_{t+1}^{i}-M_{t}^{i}\right) / p_{t+1}^{i}=y_{t+1}^{i}-y_{t}^{i}\left(u_{t}^{i^{\prime}} / u_{t+1}^{i^{\prime}}\right)$. Using these facts in (3.2) and (3.3) and letting $b$ be the common value of debt across the policy rules (assumption (c) above), the difference in expected tax collections for period $t+1$ is given by

$$
\left.E_{t}\left\{T_{t+1}^{p}-T_{t+1}^{i}\right\}=E_{t}\left\{\left[r_{t}^{p}-r_{t}^{i}\right)\right] b-\left[y_{t+1}^{p}-y_{t}^{p}\right]+\left[y_{t+1}^{i}-y_{t}^{i} u_{t}^{i^{\prime}} / u_{t+1}^{i^{\prime}}\right]\right\}
$$

Adding slightly more structure can be very helpful for determining the sign of (3.4). We have assumed that average seigniorage is zero. Making the (log of the) productivity shock follow a random walk will make expected seigniorage in any period equal to zero. Moreover, assuming that government expenditure is a constant share of GNP will make (the log of) consumption follow a random walk too. Under these assumptions, the second term in (3.4) drops out while the last term is negative when $\theta>1 .{ }^{17}$ The term inside the first set of brackets in (3.4) is the real interest rate differential. Using (2.26) and (2.27), this term can be written as

$$
r_{t}^{p}-r_{t}^{i}=0.5 \theta\left[(1-\theta) \sigma_{i}^{2}-(1+\theta) \sigma_{p}^{2}\right]
$$

where $\sigma_{i}^{2}$ and $\sigma_{p}^{2}$ are the variance of output (consumption) under interest rate and price level targeting respectively. The latter is greater than the former for the following reason. Actual

\footnotetext{
${ }^{17} E_{t}\left[y_{t+1}^{i}-y_{t}^{i} u_{t}^{i^{\prime}} / u_{t+1}^{i^{\prime}}\right]=y_{t}^{i} E_{t}\left[\varphi_{t+1}-\left(\varphi_{t+1}\right)^{\theta}\right]<1$ if and only if $\theta>1$ with $y_{t+1}^{i}=y_{t}^{i} \varphi_{t+1}$.
} 
seigniorage is countercyclical under interest rate pegging (but procyclical under a price level target): when output is unexpectedly high, inflation is unexpectedly low. The countercyclicality of seigniorage implies that income tax revenues exhibit a smaller cyclical variation, which in turn implies a lower variation for tax rates, output and consumption. Consequently, the first term in (3.4) is negative too, and hence average tax rates are always lower under price level stabilization.

Unlike the analysis of the previous section, differences in real interest rates across alternative monetary policy rules now matter for welfare and income. This is due to the fact that in the absence of lump-sum taxes, higher interest payments or public debt require higher tax collections and higher average tax rates. At the same time, the variability of tax rates and consumption is higher under price level targeting. Monetary policy is not neutral even when money is neutral in the traditional sense. Note that the real interest rate differentials that come out of the model with distortionary taxation will tend to be comparable to those obtained under lump sum taxation if the variability in consumption (and hence differences in variability across policy rules) is small.

Issuing exclusively inflation indexed bonds is equivalent to issuing nominal bonds and pursuing an inflation stabilization policy. Our analysis implies that price indexed debt -or a nominal debt/ procyclical monetary policy rule combination- has lower average debt servicing costs (and lower average tax rates) than a nominal debt/countercyclical policy combination. While it is tempting to suggest that a government facing fiscal difficulties ought to prefer the former it must be kept in mind that there is a trade off involved between average tax rates and their variability (and hence, a trade off between the level of consumption and its variability). Subsequently, as in Bohn (1988), it may be optimal for a risk averse government, or a government that maxi- 
mizes the utility of risk averse agents, to have a mixture of real and nominal debt. The exact composition depends on risk attitudes. Note also that the policymakers have two instruments at their disposal when they design the optimal debt instrument/monetary policy combination: the degree of price indexation; and the degree of cyclicality of monetary policy.

\section{Conclusion}

We have investigated the implications of alternative monetary targeting practices for real interest rates and economic activity. There seem to be important fiscal ramifications that have not been explored before. ${ }^{18}$ Differences in public debt servicing of the order of half a percentage point of GNP can be hardly overlooked.

The analysis can be extended to study models where money is not neutral. Of particular interest within this class of models are those specifications that allow macroeconomic stabilization policy to have direct effects on real economic activity, such as the Keynesian and the classical imperfect information models. What is interesting about applying our logic to these models is that it permits an integrated analysis of business cycle and long term economic activity. If policy is indeed effective, then alternative monetary rules will imply different long term real interest rates and average tax rates and different associations between the amplitude of macroeconomic fluctuations and long term output. Consequently, the present paper offers an additional mechanism to that suggested by Dellas (1992) for integrating stabilization (monetary) policy, business cycles and long term prospects.

\footnotetext{
${ }^{18}$ Note that monetary policy can also have fiscal implications because of time inconsistency and credibility problems, through the maturity structure of public debt and so on.
} 


\section{References}

[1] Aschauer, D. and J. Greenwood, 1983, "A further exploration in the theory of exchange rate regimes," Journal of Political Economy, 868-875.

[2] Bohn, H., "Why do we have nominal government debt?," Journal of Monetary Economics, $101-121$.

[3] Canzoneri, M. and H. Dellas, 1993, "Real interest rates and central bank operating procedures," KUL working paper, No 96/1994.

[4] Cooley, T.C. and G.D. Hansen, 1989, "The inflation tax in a real business cycle model," American Economic Review, 733-747.

[5] Chari, V., L. Christiano and P. Kehoe, 1991, "Optimal fiscal and monetary policy: Some recent results," Journal of Money Credit and Banking, 517-539.

[6] Dellas, H., 1992, "The long term effects of stabilization policy," mimeo, Univ. of Maryland.

[7] Friedman, M. and A. Schwartz, 1963, A Monetary History of the United States, 1867-1960, Princeton: Princeton University Press.

[8] Greenwood, J. and G. Huffman, 1987, "A dynamic equilibrium model of inflation and unemployment," Journal of Monetary Economics, 203-28.

[9] Haraf, W. and P. Cagan, 1990, Monetary Policy for a Changing Financial Environment, Washington DC: The American Enterprise Institute.

[10] LeRoy, S.F., 1984, "Nominal prices and interest rates in general equilibrium," Journal of Business, 177-213. 
[11] Lucas, R., 1982, "Interest rates and currency prices in a two country world," Journal of Monetary Economics, 112-34.

[12] Orphanides, Y. and R. Solow, 1990, "Money, inflation, and growth," in Handbook of Monetary Economics, Volume 1, edited by B.M. Friedman and F. H. Hahn, New York, NY: North Holland.

[13] Shen, P., 1998, "How important is the inflation risk premium?" Federal Reserve Bank of Kansas City Economic Review, 35-48.

[14] Sidrauski, M., 1967, "Rational choice and patterns of growth in a monetary economy," American Economic Review, 534-44.

[15] Stockman, A., 1981, "Anticipated inflation and the capital stock in a cash-in-advance economy," Journal of Monetary Economics, 387-93.

[16] Svensson, L.E.O., 1985, "Money and asset prices in a cash-in-advance economy," Journal of Political Economy, 919-994.

[17] Tobin, J., 1965, "Money and economic growth," Econometrica, 671-684.

[18] Wilson, C., 1979 "An infinite horizon model with money," in General Equilibrium Growth and Trade: Essays in honor of Lionel McKenzie, J. Green and J. Scheinkman (eds), New York: Academic Press.

[19] Woodford, M., 1990, "The optimum quantity of money," in Handbook of Monetary Economics, Volume 2, edited by B.M. Friedman and F. H. Hahn, New York, NY: North Holland. 